\title{
Hemostasis in Hypothyroidism and Autoimmune Thyroid Disorders
}

\author{
Arash Ordookhani, ${ }^{1}$ and Kenneth D. Burman ${ }^{2, *}$ \\ ${ }^{1}$ Endocrine Section, Department of Internal Medicine, Providence Hospital, Washington, DC, 20017 \\ ${ }^{2}$ Endocrine Section, MedStar Washington Hospital Center, Washington, DC, 20010 \\ "Corresponding author: Kenneth D. Burman, MD, The Endocrine Section, Rm. 2A72, MedStar Washington Hospital Center, 110 Irving St., NW, Washington, DC 20010. E-mail: \\ kenneth.d.burman@medstar.net
}

Received 2016 November 19; Revised 2017 February 11; Accepted 2017 February 15.

\begin{abstract}
Context: There are contradictory results on the effect of hypothyroidism on the changes in hemostasis. Inadequate populationbased studies limited their clinical implications, mainly on the risk of venous thromboembolism(VTE). This paper reviews the studies on laboratory and population-based findings regarding hemostatic changes and risk of VTE in hypothyroidism and autoimmune thyroid disorders.

Evidence Acquisition: A comprehensive literature search was conducted employing MEDLINE database. The following words were used for the search: Hypothyroidism; thyroiditis, autoimmune; blood coagulation factors; blood coagulation tests; hemostasis, blood coagulation disorders; thyroid hormones; myxedema; venous thromboembolism; fibrinolysis, receptors thyroid hormone. The papers that were related to hypothyroidism and autoimmune thyroid disorder and hemostasis are used in this review.

Results: Overt hypothyroidism is more associated with a hypocoagulable state. Decreased platelet count, aggregation and agglutination, von Willebrand factor antigen and activity, several coagulation factors such as factor VIII, IX, XI, VII, and plasminogen activator-1 are detected in overt hypothyrodism. Increased fibrinogen has been detected in subclinical hypothyroidism and autoimmune thyroid disease rendering a tendency towards a hypercoagulability state. Increased factor VII and its activity, and plasminogen activator inhibitor-1 are among several findings contributing to a prothrombotic state in subclinical hypothyroidism.

Conclusions: Overt hypothyroidism is associated with a hypocoagulable state and subclinical hypothyroidism and autoimmune thyroid disorders may induce a prothrombotic state. However, there are contradictory findings for the abovementioned thyroid disorders. Prospective studies on the risk of VTE in various levels of hypofunctioning of the thyroid and autoimmune thyroid disorders are warranted.
\end{abstract}

Keywords: Hypothyroidism, Thyroiditis, Autoimmune, Hashimoto Disease, Myxedema, Venous Thromboembolism, Blood Coagulation Factors, Fibrinolysis

\section{Context}

Hemostasis is an essential process that maintains the integrity of the blood stream in the human body. When a vessel wall is breached or the endothelium is disrupted, collagen and tissue factor are exposed to the blood stream. The former triggers the accumulation and activation of platelets for the formation of a hemostatic plug (primary hemostasis), whereas the latter initiates thrombin generation (secondary hemostasis), which not only converts fibrinogen to fibrin for the generation of a fibrin meshwork to stabilize the platelet thrombus, but also activates platelets (1). Disequilibrium between activators and inhibitors of the hemostatic system may result in bleeding or pathological thrombosis. Tendency to thrombosis, arterial and/or venous, is associated with increased morbidity and mortality (1). Thyroid hormones are potent mediators of numerous physiological and metabolic processes, including blood coagulation and their abnormalities can adversely affect various steps in the coagulation cascade $(2,3)$. The effect of thyroid hormone on the coagulation-fibrinolytic system is mainly mediated through interaction of the hormone and its receptors $(4,5)$.

The earliest reports on a link between thyroid disorders and coagulation abnormalities are from the early years of the past century (6-8). Since then, several studies have been conducted on thyroid function abnormalities and their effect on the hemostasis with contradictory results (9-19). The present report provides an updated and comprehensive report on hemostasis changes in hypothyroidism and autoimmune thyroid disorders.

\section{Evidence Acquisition}

The following search terms (medical subject heading, terms, and text words) were used for the MEDLINE search until March 2016: Hypothyroidism; thyroiditis, autoimmune; blood coagulation factors; blood coagulation tests; blood coagulation disorders; thyroid hormones; myxedema; venous thromboembolism; fibrinolysis, hemostasis, thyroid diseases, thyroid hormones, receptors thyroid hormone. In addition, by hand-searching ref- 
erence lists in review articles and relevant textbook chapters were searched for papers beyond 2000 . The eligibility criteria were inclusion of all types of studies that evaluated alterations in hemostatic parameters and/or occurrence of clinical hemostatic events including venous thromboembolism (VTE) and/or bleeding in hypothyroidism and/or autoimmune thyroid disorder (AIT). The authors reviewed all the titles and abstracts generated by the search engine and exclude those that were not covering the eligibility criteria. For potentially relevant studies hard copies of the full article was obtained and the studies were reviewed in detail to make sure they met the inclusion criteria. Figure 1 shows the flowchart of studies assessed and selected by two reviewers.

A total of 457 papers were cited and after exclusion 244 papers that did not meet inclusion criteria, 213 papers were thoroughly studied and in order to submit the current manuscript to this journal, the number of papers was further decreased (Figure 1). In order to prevent missing any scientific points from the omitted papers, review articles containing those scientific points were used in the manuscript's reference list. Throughout the manuscript, evidence in favor of hypercoagulability, hypocoagulability, or no alterations in hemostatic parameters, if applicable, has been provided for each thyroid-related topic.

\section{Results}

\subsection{Overt Hypothyroidism}

Primary hypothyroidism is a common disorder and is present in $0.3 \%$ of the U.S. population (20). The association of overt - and subclinical hypothyroidism with allcause mortality independent of coronary artery disease risk factors has been shown (21). The traditional theory held that inadequate thyroid hormone level contributes to atherosclerosis (22).

Both hypocoagulation and hypercoagulation have been reported in hypothyroidism; however, the results seem to be dependent on the severity of the hypothyroidism as severe hypothyroidism is accompanied with a tendency to bleeding $(7,23-30)$, whereas, moderate hypothyroidism shows a prothrombotic status (11, 16-19, 24). The markers of endothelial injury have been reported to be within normal limit in hypothyroidism and therefore, whether there is a vascular injury in hypothyroidism is unclear (31).

\subsection{Hypocoagulability}

Mild mucocutaneous bleeding (epistaxis, gum bleeding, menorrhagia, bruising) is frequently observed in overt hypothyroidism patients, mainly due to an acquired von
Willebrand syndrome type $1(32,33)$. Among the miscellaneous causes of aVWS, hypothyroidism has been associated with aVWS type 1 with a frequency of $\sim 2 \%-5 \%$ (32). In a cohort study on 90 hypothyroid patients, prevalence of aVWS was calculated as von Willebrand antigen (vWF:Ag) $\leq$ $50 \%$ and/or vWF ristocetin activity (vWF:RCo) $\leq 50 \%$. Thirtythree percent of children had VWS of whom $9 \%$ were moderate and $24 \%$ were mild form of the disease. After restoration of euthyroidism by thyroid hormone therapy, there was a significant improvement in VWF:Ag, VWF:RCo, factor VIII, and endogenous thrombin potential by $44 \%, 36 \%, 39 \%$, and $10 \%$, respectively (34). The complete relief of aVWS by treatment of hypothyroidism with thyroxine is consistent with a causal relationship (35).

Hypothyroidism has been reported to be associated with a decreased-(36), increased-(37), or an unaffected (38, 39) platelet count, as well as a decreased platelet aggregation (36) and agglutination (40). Other platelet indices and function in hypothyroidism, such as decreased adhesiveness, aggregation, platelet factor, heat production, abnormal response to aspirin, and abnormal prostaglandin production are summarized elsewhere (41). Patients with overt hypothyroidism have low levels of vWF and prolonged collagen/epinephrine closure time (CEPI-CT) and collagen/ADP closure time (CADP-CT) and CEPI/CT prolongation is reversed during levothyroxine therapy (42).

In a study on 15 overt hypothyroid, 15 subclinical hypothyroid and 15 euthyroid controls, increased bleeding time, prothrombin time (PT), activated partial thromboplastin time (aPTT), and clotting time and decreased FVIII activity (FVIII:C) and vWF activity (vWF:C) were detected in overt hypothyroid compared to control individuals. The findings related to subclinical hypothyroidism (SCH) have been discussed below under "Subclinical Hypothyroidism". Each of the above-mentioned parameters normalized after levothyroxine treatment (38).

Hypothyroidism was associated with decreased levels of FVIII, FIX, and FXI $(25,26)$, increased fibrinolytic activity (27-29), and increased plasminogen and decreased inhibition of plasminogen activator inhibitor (28). Euthyroidism following usage of levothyroxine returned these parameters to normal levels (28) and FVIII:C was increased following levothyroxine therapy (26). Mildly decreased FVIII:C and significantly decreased factor VIII-related antigen and ristocetin cofactor activity was noted in hypothyroidism with remarkable increase in their levels when treated with thyroid hormone therapy (43).

Hypothyroidism has also been associated with a decrease in factor VIII activity, vWF Antigen, vWF activity, vWF ristocetin, fibrinogen, ristocetin agglutination $(24,38,44$, 45), factor IX, XI (25), decrease in plasminogen activator inhibitor, factor VIII:C, vWF:C $(38,43)$. A recent study on thy- 


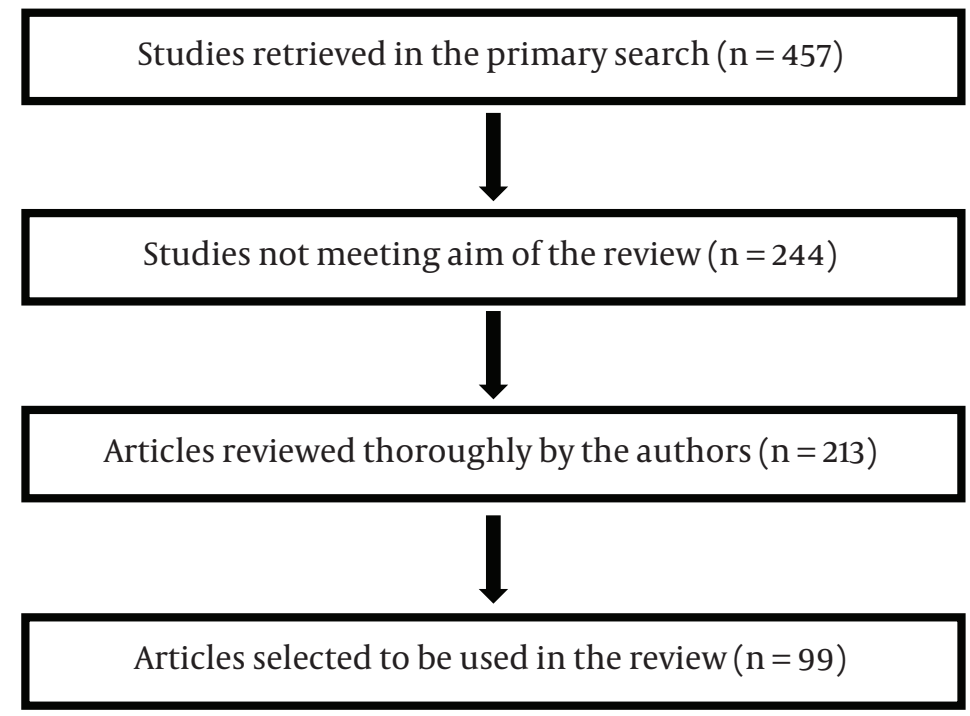

Figure 1. Flowchart of Assessment and Selection of the Studies Used in This Review

roidectomized patients with severe short-term hypothyroidism before and after receiving either levothyroxine revealed that hypothyroidism is associated with significant decrease in FVIII activity, vWF antigen, vWF activity and increased aPTT compared to the time that the patient becomes euthyroid after receiving thyroid hormone replacement therapy. Administration of recombinant human TSH (rhTSH) has no effect on coagulation factors, which suggests alteration in coagulation factors is due to thyroid hormone deficiency rather than elevation in TSH (46), although the effects of rhTSH are relatively short lived.

Compared with pretreatment values in hypothyroid patients, significant increases were noted in plasma concentrations of $\mathrm{vWF}$, fibronectin and plasma argininevasopressin (AVP) levels after levothyroxine therapy (47).

A study of 20 patients with overt hypothyroidism before and after therapy with thyroid hormones revealed a less compact fibrin structure with enhanced fibrinolysis consistent with a bleeding tendency, in hypothyroidism versus euthyroidism in the same patient (48). Fibrin clot structure/function has been shown to predict predisposition to thrombotic events, as clots with compact structure and resistance to fibrinolysis are associated with premature and more severe atherothrombotic disease (49).

Fibrinogen and PAI-1 levels are significantly lower in hypothyroid patients compared to their euthyroid state after hormone replacement therapy (48).

In rats, FVII activity (FVII:C) was significantly decreased in hypothyroid rats (50), and hypothyroidism resulted in $50 \%$ decrease of the metabolic rates of factors II, VII, and X compared to euthyroid-and thyroxin-treated hypothyroid rats. These results are suggestive of the influence of thyroid function on the synthesis rate of the protein moiety of coagulation factors and are supportive of a hypocoagulation state in hypothyroidism (51). Table 1 shows a summary of changes in hemostatic parameters attributed to hypocoagulability in overt hypothyroidism.

\subsection{Hypercoagulability or no Alteration in Hemostasis}

In contrast to the comments noted above, there are several studies that are in favor of a hypercoagulable state or a "No change" in hemostasis parameters.

In a large-scale study using data of the national hospital discharge survey (NHDS) for patients discharged from short-stay nonfederal hospitals in the United States, from 1979 to 2005, pulmonary embolism (PE) was present in 119,000 of $19,519,000$ (0.61\%) hypothyroid patients compared to $3,372,000$ of $908,805,000(0.37 \%)$ patients with no thyroid dysfunction (relative risk $=1.64,95 \%$ CI $1.63-1.65$ ). Deep venous thrombosis (DVT) was diagnosed in $1.36 \%$ of hypothyroid patients and in $0.84 \%$ of patients with no thyroid dysfunction (relative risk $=1.62,95 \%$ CI $1.61-1.62$ ). Hypothyroid patients younger than 40 years of age had the highest relative risks for PE (3.99) and DVT (2.25). This is in favor of a hypercoagulable state in hypothyroidism, however, authors commented that despite of this increase in the risk of VTE, antithrombotic prophylaxis should still be considered in the context of a possible hyperfibrinolytic state in such patients (52).

In a large-scale study, databases of linked statistical records of hospital admissions and death certificates for 
Table 1. Summary of Changes in Hemostatic Parameters Attributed to Hypocoagulability in Overt Hypothyroidism ${ }^{\mathrm{a}}$

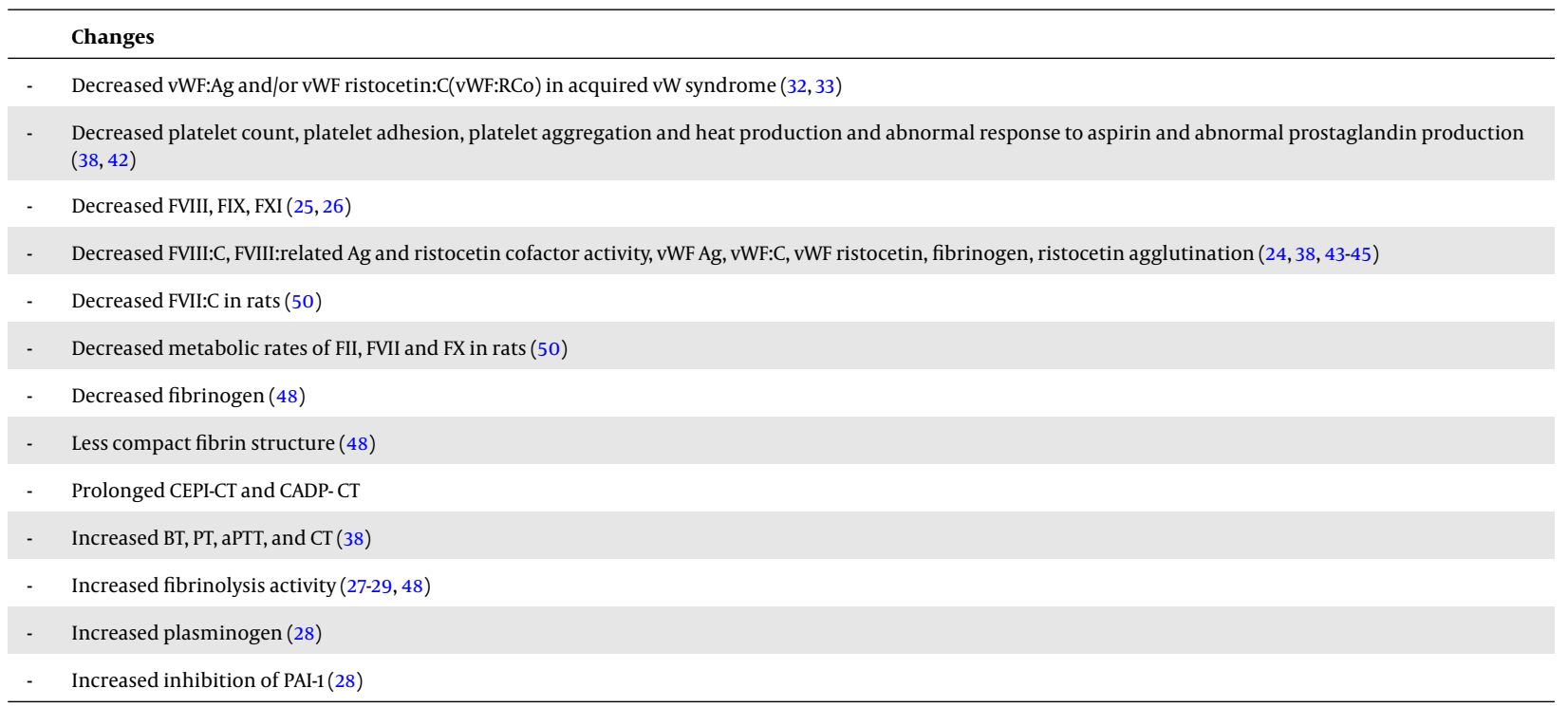

Abbreviations: Ag, antigen; aPTT, activated partial thromboplastin time; BT, bleeding time; C, activity; CADP-CT, collagen/ADP closure time; CEPI-CT, collagen/epinephrine closure time; CT, clotting time; F, factor; PT, prothrombin time; vW, von Willebrand.

${ }^{\mathrm{a}}$ References are shown in parenthesis.

Figure 2. Mechanisms contributing in hypocoagulability in overt- and subclinical hypothyrodism*

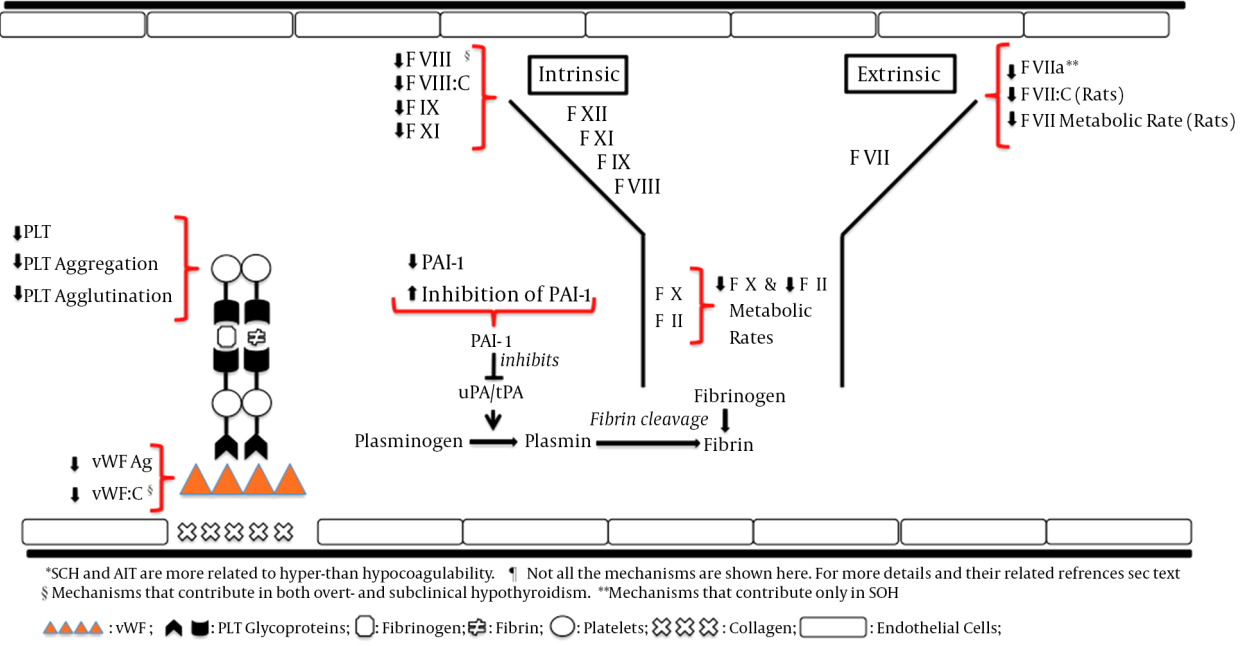

SCH: subclinical hypothyroidism; AIT: autoimmune thyroiditis; PLT, platetes; F, coagulation factor; FVIII:C, FVIII activity; FVII:C, FVII activity; FVIIa: activated FVII; PAI-1: plasminogen activator inhibitor 1; vWF: von Willebrand factor; vWF:C: vWF activity; Ag, antigen; uPA, Urokinase-type plasminogen activator; tPA: tissue plasminogen activator.

the Oxford record linkage study area (ORLS1: 1968 to 1998 and ORLS2: 1999 to 2008) and the whole of England (1999 to 2008) were analyzed. There was a significant elevation of risk of venous thromboembolism (VTE) among patients with myxedema in all three populations with rate ratio
(95\% CI) of 1.47 (1.27 - 1.70, P $<0.001)$ for ORLS1 population, $1.36(1.22-1.52, \mathrm{P}<0.001)$ for ORLS2 population, and 1.30 (1.27 $-1.33, \mathrm{P}<0.001)$ for England data set (53). Additionally, cerebral vein thrombosis has been reported in hypothyroidism (54). 
Although a decrease in levels of serum thyroxine was accompanied by a decrease in factor VIII in "Mild to moderate" hypothyroidism, euglobulin lysis time was correspondingly prolonged, suggesting a hypofibrinolysis. There was also a reciprocal correlation between thyroid antibody titers and fibrinolysis (55). Another study on overt hypothyroidism showed an imbalance between indicators of thrombin and plasmin activity (i.e., fibrinopeptide $\mathrm{A}$ and fibrinopeptide $\mathrm{B} ß$ ) in favor of a hypercoagulable state (17). Free thyroxin levels were reciprocally correlated with levels of plasma D-dimer and plasminogen activator inhibitor-1 (PAI-1) and activity of factor VII (FVII:C) and factor VIII (FVIII:C). These findings were suggestive of a hypercoagulable state (56). High fibrinogen levels and elevated FVII activity are suggestive of hypercoagulability (57). There was a negative and independent relationship between fibrinogen and FT4 in 959 patients and it was consistent with a tendency to a more coagulable state in patients with normal-low FT4 levels compared with those with normal-high FT4 levels (58).

Thrombin-activatable fibrinolysis inhibitor (TAFI) is the protein that links coagulation and fibrinolytic system. TAFI is a glycoprotein that is synthesized in the liver and circulates in the plasma as a carboxypeptidase B-like proenzyme. Thrombin activates TAFI and activated TAFI (TAFIa) protects the fibrin clot against lysis (59), thus acting as a "Fibrinolysis inhibitor". This anti-fibrinolytic function is based on cleavage of C-terminal lysine residues of partly degraded fibrin, the binding site of plasminogen and its activator, tissue plasminogen activator (t-PA). This process results in less plasmin formation. TAFI attenuates the fibrinolytic system by inhibiting the binding of plasminogen to fibrin and attenuation of fibrin-plasminogen interaction that causes inhibition of fibrinolysis and a tendency to thrombosis (59-62). The elevation of TAFI antigen is a cause of hypofibrinolysis in several endocrinological disorders $(63,64)$. Elevated TAFI antigen levels were detected in overt hypothyroidism, suggesting fibrinolysis inhibition and levothyroxine treatment was effective in reducing these levels (65-67). TAFI antigen and activated TAFI (TAFIa) levels were significantly elevated in hypothyroid compared to control group patients and these levels decreased by levothyroxine therapy. PAI-1 and t-pA, however, were similar between two groups. The authors believe that fibrinolytic activity substantially decreases when hypothyroidism gets more severe and thyroid hormone therapy to restore euthyroidism may be important in ameliorating the increased risk of cardiovascular events (62).

The majority of the studies noted were conducted on adults. An observational study on children aged $0-16$ months revealed a significant increase in TAFI antigen levels and a significant decrease in tissue factor pathway in- hibitor (TFPI) antigen and thrombomodulin antigens levels in hypothyroid infants compared to healthy children that is consistent with subclinical hypercoagulability and hypofibrinolysis states. The abnormal coagulation parameters in hypothyroid children returned to normal upon levothyroxine therapy with the highest impact on correction of TFPI among hypothyroid subjects (68).

In a study on 15 untreated hypothyroid subjects versus age-matched healthy controls, increased factor VII, thrombomodulin, and TAFI and decreased factor V, factor VIII, $\mathrm{vWF}$, protein $\mathrm{C}$, protein $\mathrm{S}$, and tissue factor pathway inhibitor, representing a potential hypercoagulable and hypofibrinolytic state and, possible endothelial dysfunction, was found which might augment the risk for atherosclerotic and atherothrombotic complications (66).

Moderate hypothyroidism was associated with decreased fibrinolytic activity, as reflected by lower D-dimer levels, higher alpha-2 antiplasmin activities, and higher levels of t-PA and PAI-1 antigen (PAI-1 Ag). On the contrary, severe hypothyroidism was accompanied with higher Ddimer levels, lower alpha-2 antiplasmin activities, and lower t-PA and PAI-1 Ag levels. These results were not accounted for by confounding factors such as age, smoking, and components of the insulin resistance syndrome (9-11, $14,15,17,18,24,38,56,62,69)$.

The large cross sectional study of health in pomerania in Germany showed higher plasma fibrinogen in elevated TSH group. Forty-three subjects with mean TSH of $12.56 \pm$ 18.59 (normal: $0.3-3$ ) $\mathrm{mU} / \mathrm{L}$ and free $\mathrm{T} 4$ of $0.9 \pm 0.34$ (normal: 0.8 - 2.0) ng/dL were grouped as elevated TSH or hypothyroid patients. The manuscript has not provided what percentage of hypothyroid patients were subclinical, mild, moderate, or severe. Based on the mean values of TSH and free T4 it appears that hypothyroidism likely had moderate severity. If so, this is in support of a hypercoagulable state in this group of hypothyroid individuals (70). Hypothyroid rats showed significantly increased tissue factor activities, which may have another risk factor for cardiovascular diseases (50).

In a case-control study in Sudan, hypothyroid patients showed decreased PT and no significant change in aPTT, plasma fibrinogen levels, and platelet counts (71). Hypothyroid patients under treatment with levothyroxine and normal free T4 and free T3 were classified into three groups based on their TSH levels $(0.4-<2,2-<5.5$, and $5.5-<$ $20 \mathrm{mU} / \mathrm{L}$, respectively) and they did not show any differences in their fibrinogen and D-dimer levels (72). Hypothyroidism was associated with a non-significant change in plasminogen activator, antiplasmin (a plasmin inhibitor), and fibrinogen levels (28).

The findings of an experimental study conducted on rats following injections of TRH, TSH, T3, and T4 subcuta- 
neously for three days adds more confusion to the already contradictory results. TSH did not have any significant effect on factors II, VII, IX, X in rats, whereas TRH and T3 significantly reduced activities of the aforementioned factors. T4 had only a significant effect on reduction of FII activity. However, TRH, TSH, T3, and T4 each one individually prolonged aPTT and PT significantly, which suggests possible effects of these hormones on other factors in intrinsic and extrinsic coagulation pathways (73).

The mechanism(s) underlying changes in coagulation parameters in hypothyroidism is not well established. A proposed mechanism is direct effect of thyroid hormones as there are several studies in favor of a prothrombotic effect of thyroid hormones in the literature $(19,38,44,69)$. However, it has been unclear as to whether a deficiency in thyroid hormone levels or an elevated TSH (or both) contributes to alterations in coagulation parameters. An experimental study on rats did not show any significant effect of TSH on factors (F) II, FVII, FIX, FX, while T3 caused significantly reduced activities of the factors and $\mathrm{T} 4 \mathrm{had}$ the same effect on only FII (73).

In a meta-analysis on thyroid dysfunction and hemostasis alterations, the studies with a "Moderatequality" revealed that hypothyroidism is associated with increased bleeding time, PT, aPTT, clotting time and decrease in FVIII:C, vWF Ag, vWF activity (vWF:C), vWF ristocetin, fibrinogen, and ristocetin agglutination (24). However, using meta-analysis on observational studies is controversial (74).

Several changes in plasma levels of of antiplasmin, tissue-type plasminogen activator (t-PA), plasminogen activator inhibitor 1(PAI-1), and D-dimer have been described earlier, which suggest thyroid hormone deficiency may affect fibrinolytic system as well $(18,24,59)$. However, the net effect of deficiency of thyroid hormone on fibrinolytic activity remains unclear $(24,75)$.

In summary, the most common coagulation disorder in overt hypothyroidism is acquired vonWillebrand's disease. Reduced levels of FIX, FX, and FXI are reported (15, $24,26,38,76$ ). Evidence regarding other coagulation parameters is less robust but increased fibrinogen activity, decreased or no change in fibrinogen levels and reduced levels of other coagulation factors have been reported (9$11,14,15,17,18,24,27,28,38,56,69)$.

\subsection{Subclinical Hypothyroidism}

Subclinical hypothyroidism (SCH) defined as elevated TSH with normal levels of free T4 and T3 has been related to enhanced atherogenesis and is found in $4.3 \%$ of the U.S. population (20).

\subsection{Hypercoagulability}

$\mathrm{SCH}$ has been shown to be an independent risk factor for atherosclerosis and myocardial infarction $(77,78)$. A retrospective cohort analysis on 6408 consecutive patients from the PreCIS (preventive cardiology information system, cleveland clinic) database suggested patients at highrisk for coronary artery disease who suffer from either hypothyroidism or moderate, and not mild, $\mathrm{SCH}$ need to be treated with levothyroxine as they have increased all-cause mortality independent of coronary heart disease (21). Interestingly, in the same study, fibrinogen levels were significantly higher in moderate $\mathrm{SCH}$ and hypothyroid groups at the initial visit (21). A possible increased risk of cardiovascular disorders has been proposed in patients with subclinical hypothyroidism, suggesting of a prothrombotic effect being involved $(18,56)$. On the other hand, the role of coagulation-fibrinolytic system in the pathophysiology of atherosclerosis and arterial thrombosis is still unresolved $(79,80)$. Additionally, whether arterial and venous thromboembolism share common risk factors and a common pathophysiology remains to be clarified (80). It has been hypothesized that $\mathrm{SCH}$ leads to coagulation disorders and deep venous thrombosis, which can explain some cases of sudden death associated with pulmonary embolism without other significant risk factors of coagulation disorder (81). A pilot study on 50 individuals with unprovoked deep vein thrombosis (DVT), 50 individuals with provoked DVT, and 50 controls showed unrecognized SCH in $14 \%$ of unprovoked DVT and $2 \%$ of the provoked DVT and controls. This report suggests an increased prevalence of $\mathrm{SCH}$ in unprovoked DVT (33). The clinical relevance of this finding requires prospective studies. Several results have already associated SCH with an increased thrombotic risk $(24,75)$. The changes in hemostatic parameters may be the contributing factor in increasing the risk of cardiovascular events $(35,69,77,82)$.

Whether elevated serum TSH contributes to the atherogenesis remains to be further evaluated. There is evidence against and in favor of this possible role. Elevated TSH can promote vascular smooth muscle cell proliferation through the cAMP-dependent pathway. This may contribute to atherogenic effect of TSH (83). On the contrary, in an experimental study on rats, injections of TSH subcutaneously for three days did not have any significant effect on factors II, VII, IX, X in rats, whereas significantly prolonged activated partial thromboplastin time (aPTT) and prothrombin time (PT) (73). Administration of levothyroxine or recombinant human TSH (rhTSH) to thyroidectomized patients revealed that rTSH has no effect on coagulation parameters (i.e., fibrinogen, platelets, thrombin time, PT, international normalized ratio (INR), aPTT, vWF activity, vWF antigen, and FVIII activity) compared to their 
hypothyroid status before receiving rhTSH (46).

Several studies have reported alterations of the coagulation system in overt hypothyroidism and $\mathrm{SCH}$ and it appears that it is dependent on the degree of the severity of thyroid dysfunction (84). Overt hypothyroidism has a tendency towards bleeding whereas, SCH towards a hypercoagulable state $(18,24,56,75,85)$. Although the latter assumption could not be supported in a meta-analysis on medium-quality observational studies, as FVIII:C and vWF ristocetin were decreased in individuals with $\mathrm{SCH}$, whereas there was no change in bleeding time, aPTT, PT, and clotting time (24).

Significantly higher levels of FVII, FVII activity (FVII:C), and the ratio of FVII:C to FVII antigen (FVII:Ag) were observed in patients with SCH compared to euthyroid controls. The latter might reflect the presence of activated FVIIa, and consequently a hypercoagulable state, which could contribute to the increased prevalence of coronary heart disease reported in such patients (69). Increased levels of fibrinogen, PAI-1, and factor VII and decreased levels of antithrombin-III (ATIII) activity in patients with SCH compared to controls were compatible with hypofibrinolytic and hypercoagulable states in SCH. Levothyroxine treatment significantly decreased PAI-1 and factor VII levels (86). A pilot study on the effect of SCH on patients who take vitamin Kantagonists suggests that SCH may have an effect on both sensitivity and stability of vitamin K-antagonist anticoagulants. Therefore, it is plausible that some patients with unstable INRs would suffer from unrecognized $\mathrm{SCH}(87)$.

Elevated TAFI antigen levels, suggesting of a hypofibrinolytic state, were detected in SCH (88). Global fibrinolytic capacity was significantly lower in 14 subclinical hypothyroid cases compared to 14 healthy controls (89). Elevated plasma levels of TAFI antigen in subclinical hypothyroidism may be associated with hypofibrinolysis and elevated risk of thrombosis. Normalization of thyroid state following levothyroxine replacement seems to be effective in lowering of TAFI antigen levels (65). Elevated TAFI antigen and TAFI activity suggest a hypofibrinolysis and a thrombogenic situation in SCH (62). Decreased fibrinolytic activity, expressed by lower D-dimer levels, higher alpha2 antiplasmin, and increased levels of tissue plasminogen activator inhibitor antigen was identified in moderate to severe hypothyroidism (18). Table 2 shows a summary of hemostatic changes attributed to a prothrombotic state in $\mathrm{SCH}$.

\subsection{Hypocoagulability or no Alteration in Hemostasis}

A case control study on $15 \mathrm{SCH}$ and 15 euthyroid controls revealed significantly lower FVIII and vWF activities in $\mathrm{SCH}$ compared to controls, which is in favor of a bleeding tendency. However, bleeding time and PT were similar between SCH and controls (38).

In a large Danish population-based study, plasma levels of fibrinogen, PAI-1, vWF, and tPA antigen between $249 \mathrm{SCH}$ individuals (defined as TSH of 2.81-10 mU/L and normal T4 and T3) compared to euthyroid controls (normal reference TSH of $0.60-2.80 \mathrm{mU} / \mathrm{L}$ ) showed no statistical difference (78). In the 5th Tromso epidemiological study, mild SCH in 88 patients showed $10 \%$ lower levels of activated FVII (FVIIa) compared to 141 euthryroid controls. This is supportive of a bleeding tendency. Although the authors assume that this coagulation abnormality may contribute to atherogenesis, they also mentioned that the prognostic value of the low FVIIa remains to be established. In contrast to other studies on SCH, PAI-1 was slightly elevated compared to control group. However, the previous studies had higher TSH levels in their case group compared to this study. In this study, the rest of the coagulation parameters such as tissue plasminogen activator antigen (tPA Ag), PAI-1, prothrombin fragment $1+2(\mathrm{~F} 1+2)$, and total FVII coagulant activity (FVII:C) were similar between cases and controls (92). No differences could be found in coagulation/fibrinolysis parameters between patients with $\mathrm{SCH}$ and control subjects (77). These parameters include PT, aPTT, fibrinogen, FV, FVII, FVIII, FIX, and FX activities, vWF, antithrombin III (AT III), protein C, protein S, tissue plasminogen activator (t-PA) and PAI-1 (77). In a study of hypothyroid patients undergoing treatment with levothyroxine, there was no difference in fibrinogen and D-dimer levels between various levels of TSH compared to controls. These case groups were stratified into TSH levels of 0.4 to $2 \mathrm{mU} / \mathrm{L}$ (group $1 ; \mathrm{n}=154$ ), TSH levels of 2 to $<5.5 \mathrm{mU} / \mathrm{L}$ (group $2 ; \mathrm{n}=176$ ), and TSH levels of 5.5 to $<20 \mathrm{mU} / \mathrm{L}$ and normal free T3 and free T4 level (group 3; $\mathrm{n}=72$ ). The latter group had a biochemical picture similar to patients with $\mathrm{SCH}$ (72). Total and free tissue factor pathway inhibitor (TFPI), PAI-1, tissue plasminogen activator (tPA) levels were similar in SCH and controls (14). In a study in Sudan, PT, aPTT, fibrinogen, and platelet counts were not different between subclinical- and overt hypothyroidism (71).

\subsection{Autoimmune Thyroid Disorder}

Subclinical hypothyroidism and autoimmune thyroiditis (AIT) has been reported in a patient with cerebral venous thrombosis (85).

Elevated mean fibrinogen levels were observed in patients with euthyroid Hashimoto's thyroiditis compared to euthyroid controls (90).

It has been hypothesized that patients with hypothyroidism and autoimmune thyroiditis are at increased risk of cardiovascular events and a recent meta-analysis re- 
Table 2. Summary of Changes in Hemostatic Parameters Attributed to Hypercoagulability in Subclinical Hypothyroidism and Autoimmune Thyroid Disorders ${ }^{\text {a }}$

\begin{tabular}{|c|c|}
\hline & Changes \\
\hline - & Subclinical hypothyroidism \\
\hline- & Increased fibrinogen level $(21,86)$ \\
\hline- & Increased FVII, FVII:C, ratio of FVII:C to FVII Ag [reflecting increased activated FVII] (69) \\
\hline - & Increased PAI-1 (86) \\
\hline - & Increased TAFI Ag $(62,88)$ \\
\hline - & Increased TAFI:C (62) \\
\hline- & Decreased antithrombin-III:C (86) \\
\hline- & Decreased global fibrinolytic capacity (89) or activity (18) \\
\hline- & Autoimmune thyroid disorders \\
\hline- & Increased fibrinogen level (90) \\
\hline- & Increased fibrinopeptide $\mathrm{A}$ and fibrinopeptide $\mathrm{B} \beta$ 15-42 (91) \\
\hline - & Increased mean platelet volume (12) \\
\hline
\end{tabular}

Abbreviations: Ag, antigen; C, activity; F, factor; PAI-1, plasminogen activator inhibitor 1; TAFI, thrombin activatable fibrinolysis inhibitor. ${ }^{a}$ References are shown in parenthesis.

vealed an increased risk of approximately $20 \%$ for coronary heart disease (93).

Unlike coronary heart disease, there have been few epidemiologic studies on assessment of association between hypothyroidism/AIT and an increase in risk of cerebrovascular disease. These reports, mostly small studies, showed conflicting results and had methodological limitations (7, 88). Autoimmune pathology in AIT might itself affect cerebrovascular risk, as it has been previously shown for other autoimmune disorders (23).

In a large-scale epidemiological study there was a slight but significantly elevated risk of VTE among patients with Hashimoto's thyroiditis in England data set with a rate ratio of $1.41(95 \% \mathrm{CI}, 1.15-1.72, \mathrm{P}=0.001)$. Neither ORLS1 nor ORLS2 showed similar finding (for details see "Hypothyroidism") (53).

A large-scale case-control study showed that AIT slightly increases the risk of stroke independent of cardiovascular risk factors; however, a limitation of this study was that it could not discriminate cases with hemorrhagic or ischemic stroke. The "Stroke code" in the UK database did not specify subtype (94).

Higher levels of fibrinogen, fibrinopeptide $A$, and fibrinopeptide $\mathrm{B} \beta$ 15-42 were found in toxic nodular goiter (with $74 \%$ antimicrosomal antibody positivity) compared to controls (91). Both increased antiphospholipid antibodies and enhanced thrombin activity may contribute to hypercoagulable state in Grave's disease (95).

Recently, it has been shown that mean platelet volume in euthyroid patients with Hashimoto's thyroiditis is sig- nificantly higher than the healthy controls (96). It has been reported that mean platelet volume was correlated with anti-thyroid peroxidase antibody (TPOAb) in Graves' disease (12). Table 2 shows a summary of hemostatic changes attributed to a hypercoagulability in $\mathrm{SCH}$.

There might be an interference of thyroid autoantibodies in metabolism of warfarin or instead, on the in vitro measurement of the international normalized ratio and the quality of laboratory control (97). Some authors consider that autoimmune disorders, in general, render a hypercoagulable state. A large-scale population-based retrospective cohort study in Sweden showed that autoimmune disorders are associated with a high risk of pulmonary embolism in the first year after hospital admission, suggesting a hypercoagulable state (98). It is noteworthy to keep in mind that AIT maybe associated with other thyroidassociated autoimmune coagulation disorders and a coagulation evaluation including platelet count, aPTT and antiphospholipid sydrome is suggested (99).

\section{Overall Conclusions}

There is a census on a hypocoagulable state in overt hypothyroidism and a prothrombotic state in SCH and AIT. Figure 2 shows some of the changes in hemostatic parameters that may contribute to hypocoagulability in overtand subclinical hypothyroidism. However, there are several studies contradicting the above-mentioned findings. Lack of clinical implications has increased this conflict. Whether various levels of hypothyroidism severity and/or 
AIT would significantly predispose to bleeding or VTE, yet to be proven. A study on SCH and occurrence of VTE has a clinical importance. If SCH would have been proven to be a risk factor for VTE, this can change clinical practice and management of the patients as VTE would be re-classified as "Provoked" or "Non-provoked" based on the presence or absence of SCH. The prospective studies would be more informative if hemostatic parameters would be measured in regular intervals during the study.

\section{Acknowledgments}

We are thankful to Mr. Fred King, Medical Librarian at Medstar Washington hospital Center and Ms. RoseMarie Leone Winiewicz, Director of Guha MD Medical Library for their technical assistance.

\section{Footnote}

Conflict of Interest: None to declare.

\section{References}

1. Furie B, Furie BC. Mechanisms of thrombus formation. $N$ Engl J Med. 2008;359(9):938-49. doi: 10.1056/NEJMra0801082. [PubMed: 18753650].

2. Hulbert AJ. Thyroid hormones and their effects: a new perspective. Biol Rev Camb Philos Soc. 2000;75(4):519-631. [PubMed: 11117200].

3. Vescovi PP, Favaloro EJ, Lippi G, Garofano M, Montagnana M, Manzato $\mathrm{F}$, et al. The spectrum of coagulation abnormalities in thyroid disorders. Semin Thromb Hemost. 2011;37(1):7-10. doi: 10.1055/s-00301270065. [PubMed: 21249600].

4. Erem C. Coagulation and fibrinolysis in thyroid dysfunction. Endocrine. 2009;36(1):110-8. doi: 10.1007/s12020-009-9185-z. [PubMed: 19367377].

5. Shih $\mathrm{CH}$, Chen SL, Yen CC, Huang YH, Chen CD, Lee YS, et al. Thyroid hormone receptor-dependent transcriptional regulation of fibrinogen and coagulation proteins. Endocrinology. 2004;145(6):2804-14. doi: 10.1210/en.2003-1372. [PubMed:14977860].

6. Doyle JB. Obstruction of the Longitudinal Sinus. Arch Neurol Psychiatr 1927;18(3):374. doi: 10.1001/archneurpsyc.1927.02210030054004.

7. Squizzato A, Gerdes VE, Brandjes DP, Buller HR, Stam J. Thyroid diseases and cerebrovascular disease. Stroke. 2005;36(10):2302-10. doi: 10.1161/01.STR.0000181772.78492.07. [PubMed: 16179578].

8. Kaliebe H. Autochthone Sinusthrombose bei einem Falle von Morbus Basedow und Tabes. Med Klin. 1913;2:1929.

9. Marongiu F, Cauli C, Mariotti S. Thyroid, hemostasis and thrombosis. J Endocrinol Invest. 2004;27(11):1065-71. doi: 10.1007/BF03345311. [PubMed: 15754740].

10. Franchini M. Hemostasis and thyroid diseases revisited. J Endocrinol Invest. 2004;27(9):886-92. doi: 10.1007/BF03346287. [PubMed: 15648557].

11. Franchini M. Hemostatic changes in thyroid diseases: haemostasis and thrombosis. Hematology. 2006;11(3):203-8. doi: 10.1080/10245330600667591. [PubMed: 17325963].

12. Erem C, Ersoz HO, Karti SS, Ukinc K, Hacihasanoglu A, Deger O, et al. Blood coagulation and fibrinolysis in patients with hyperthyroidism. J Endocrinol Invest. 2002;25(4):345-50. doi: 10.1007/BF03344016. [PubMed: 12030606].
13. Hofbauer LC, Heufelder AE. Coagulation disorders in thyroid diseases. Eur J Endocrinol. 1997;136(1):1-7. [PubMed: 9037116].

14. Ozcan MA, Comlekci A, Demirkan F, Yuksel F, Sari I, Demir T, et al. Plasma levels of free tissue factor pathway inhibitor in patients with various thyroid disorders. Thromb Res. 2003;110(4):243-7. [PubMed: 14512089].

15. Erem C, Kavgaci H, Ersoz HO, Hacihasanoglu A, Ukinc K, Karti SS, et al. Blood coagulation and fibrinolytic activity in hypothyroidism. Int J Clin Pract. 2003;57(2):78-81. [PubMed:12661786].

16. Marongiu F, Conti M, Mameli G, Murtas ML, Balzano S, Sorano G, et al. Fibrinogen and fibrinolytic activity in hyperthyroidism before and after antithyroid treatment. J Endocrinol Invest. 1988;11(10):723-5. doi: 10.1007/BF03350928. [PubMed: 2466071].

17. Marongiu F, Biondi G, Conti M, Murtas ML, Mameli G, Sorano GG, et al. Is a hypercoagulable state present in hypothyroidism?. Thromb Haemost. 1992;67(6):729. [PubMed:1509420].

18. Chadarevian R, Bruckert E, Leenhardt L, Giral P, Ankri A, Turpin G. Components of the fibrinolytic system are differently altered in moderate and severe hypothyroidism. J Clin Endocrinol Metab. 2001;86(2):732-7. doi: 10.1210/jcem.86.2.7221. [PubMed: 11158038]

19. Horne M3, Singh KK, Rosenfeld KG, Wesley R, Skarulis MC, Merryman $\mathrm{PK}$, et al. Is thyroid hormone suppression therapy prothrombotic?.J Clin Endocrinol Metab. 2004;89(9):4469-73. doi: 10.1210/jc.2004-0536. [PubMed: 15356049].

20. Hollowell JG, Staehling NW, Flanders WD, Hannon WH, Gunter EW, Spencer CA, et al. Serum TSH, T(4), and thyroid antibodies in the United States population (1988 to 1994): National Health and Nutrition Examination Survey (NHANES III). J Clin Endocrinol Metab. 2002;87(2):489-99. doi:10.1210/jcem.87.2.8182. [PubMed: 11836274].

21. McQuade C, Skugor M, Brennan DM, Hoar B, Stevenson C, Hoogwerf BJ. Hypothyroidism and moderate subclinical hypothyroidism are associated with increased all-cause mortality independent of coronary heart disease risk factors: a PreCIS database study. Thyroid. 2011;21(8):837-43. doi: 10.1089/thy.2010.0298. [PubMed: 21745107].

22. Ichiki T. Thyroid hormone and atherosclerosis. Vascul Pharmacol. 2010;52(3-4):151-6. doi: 10.1016/j.vph.2009.09.004. [PubMed: 19808101].

23. Frostegard J. Atherosclerosis in patients with autoimmune disorders. Arterioscler Thromb Vasc Biol. 2005;25(9):1776-85. doi: 10.1161/01.ATV.0000174800.78362.ec. [PubMed: 15976324].

24. Squizzato A, Romualdi E, Buller HR, Gerdes VE. Clinical review: Thyroid dysfunction and effects on coagulation and fibrinolysis: a systematic review. J Clin Endocrinol Metab. 2007;92(7):2415-20. doi: 10.1210/jc.2007-0199. [PubMed: 17440013].

25. Egeberg O. Thyroid Function and Hemostasis. Scand J Clin Lab Invest. 1964;16:511-2. [PubMed: 14209210].

26. Simone JV, Abildgaard CF, Schulman I. Blood coagulation in thyroid dysfunction. N Engl J Med. 1965;273(20):1057-61. doi: 10.1056/NEJM196511112732001. [PubMed: 5834816].

27. Hume R. Fibrinolytic Activity and Thyroid Function. $\mathrm{Br}$ Med $\mathrm{J}$. 1965;1(5436):686-8. [PubMed: 14245204].

28. Bennett NB, Ogston CM, McAndrew GM. The thyroid and fibrinolysis. BrMed J. 1967;4(5572):147-8. [PubMed: 4168723].

29. Rennie JA, Bewsher PD, Murchison LE, Ogston D. Coagulation and fibrinolysis in thyroid disease. Acta Haematol. 1978;59(3):171-7. [PubMed: 416638].

30. Akinci B, Comlekci A, Ozcan MA. The alteration of coagulation in patients with thyroid dysfunction. Recent Pat Endocr Metab Immune Drug Discov. 2011;5(1):50-7. [PubMed: 22074577]

31. Gazdag A, Nagy EV, Burman KD, Paragh G, Jenei Z. Improved endothelial function and lipid profile compensate for impaired hemostatic and inflammatory status in iatrogenic chronic subclinical hyperthyroidism of thyroid cancer patients on L-t4 therapy. Exp Clin Endocrinol Diabetes. 2010;118(6):381-7. doi: 10.1055/s-0029-1224156. [PubMed: 19658059]. 
32. Federici AB. Acquired von Willebrand syndrome associated with hypothyroidism: a mild bleeding disorder to be further investigated. Semin Thromb Hemost. 2011;37(1):35-40. [PubMed: 21305800].

33. Squizzato A, Romualdi E, Piantanida E, Gerdes VE, Buller HR, Tanda $M$, et al. Subclinical hypothyroidism and deep venous thrombosis. A pilot cross-sectional study. Thromb Haemost. 2007;97(5):803-6. [PubMed: 17479191].

34. Stuijver DJ, Piantanida E, van Zaane B, Galli L, Romualdi E, Tanda ML, et al. Acquired von Willebrand syndrome in patients with overt hypothyroidism: a prospective cohort study. Haemophilia. 2014;20(3):326-32. doi: 10.1111/hae.12275. [PubMed: 24118466].

35. Mina A, Favaloro EJ, Koutts J. Hemostatic dysfunction associated with endocrine disorders as a major risk factor and cause of human morbidity and mortality: a comprehensive meta-review. Semin Thromb Hemost. 2007;33(8):798-809. doi: 10.1055/s-2007-1000372. [PubMed: 18175285].

36. Sjoberg RJ, Kidd GS, Swanson EW, O’Barr TP, Corby DG, Hofeldt FD. Effects of hypothyroidism and short-term aging on whole blood thromboxane and arterial prostacyclin synthesis. J Lab Clin Med. 1987;110(5):576-82. [PubMed: 3668359].

37. van Doormaal JJ, van der Meer J, Oosten HR, Halie MR, Doorenbos H. Hypothyroidism leads to more small-sized platelets in circulation. Thromb Haemost. 1987;58(4):964-5. [PubMed:3445228].

38. Gullu S, Sav H, Kamel N. Effects of levothyroxine treatment on biochemical and hemostasis parameters in patients with hypothyroidism. Eur J Endocrinol. 2005;152(3):355-61. doi: 10.1530/eje.1.01857. [PubMed: 15757851].

39. Endo Y. Relationship between thyroid function and platelet counts. Acta Haematol. 1985;74(1):58-9. [PubMed: 3934911].

40. Oliveira MC, Kramer CK, Marroni CP, Leaes CGS, Viana L, Roithman S, et al. Acquired Factor VIII and von Willebrand Factor(aFVIII/VWF) Deficiency and Hypothyroidism in a Case With Hypopituitarism. Clin Appl Thrombos Hemostasis. 2010;16(1):107-9. doi:10.1177/1076029608319948.

41. Ford HC, Carter JM. Haemostasis in hypothyroidism. Postgrad Med J. 1990;66(774):280-4. [PubMed: 2201013].

42. Homoncik M, Gessl A, Ferlitsch A, Jilma B, Vierhapper H. Altered platelet plug formation in hyperthyroidism and hypothyroidism. $J$ Clin Endocrinol Metab. 2007;92(8):3006-12. doi: 10.1210/jc.2006-2644. [PubMed: 17488803].

43. Rogers J2, Shane SR, Jencks FS. Factor VIII activity and thyroid function. Ann Intern Med. 1982;97(5):713-6. [PubMed: 6814317].

44. Nagasaki T, Inaba M, Henmi Y, Kumeda Y, Ueda M, Tahara $H$, et al. Change in von Willebrand factor and carotid intima-media thickness in hypothyroid patients with normal thyroid function after levothyroxine replacement therapy. Eur JEndocrinol. 2004;150(2):12531. [PubMed: 14763909].

45. Nagasaki T, Inaba M, Kumeda Y, Ueda M, Hiura Y, Tahara H, et al. Decrease of arterial stiffness at common carotid artery in hypothyroid patients by normalization of thyroid function. Biomed Pharmacother. 2005;59(1-2):8-14. doi: 10.1016/j.biopha.2004.11.001. [PubMed: 15740929].

46. Yango J, Alexopoulou O, Eeckhoudt S, Hermans C, Daumerie C. Evaluation of the respective influence of thyroid hormones and TSH on blood coagulation parameters after total thyroidectomy. Eur J Endocrinol. 2011;164(4):599-603. doi: 10.1530/EJE-10-0837. [PubMed: 21257724].

47. Arnaout MA, Awidi AS, el-Najdawi AM, Khateeb MS, Ajlouni KM. Arginine-vasopressin and endothelium-associated proteins in thyroid disease. Acta Endocrinol (Copenh). 1992;126(5):399-403. [PubMed: 1621482].

48. Stuijver DJ, Hooper JM, Orme SM, Van Zaane B, Squizzato A, Piantanida E, et al. Fibrin clot structure and fibrinolysis in hypothyroid individuals: the effects of normalising thyroid hormone levels. J Thromb Haemost. 2012;10(8):1708-10. doi: 10.1111/j.15387836.2012.04789.x. [PubMed: 22631859].

49. Ajjan R, Lim BC, Standeven KF, Harrand R, Dolling S, Phoenix F, et al. Common variation in the C-terminal region of the fibrinogen beta-chain: effects on fibrin structure, fibrinolysis and clot rigidity. Blood. 2008;111(2):643-50. doi: 10.1182/blood-2007-05-091231. [PubMed: 17925485].

50. Alturfan AA, Alturfan EE, Dariyerli N, Zengin E, Aytac E, Yigit G, et al. Investigation of tissue factor and other hemostatic profiles in experimental hypothyroidism. Endocrine. 2006;30(1):63-7. doi 10.1385/ENDO:30:1:63. [PubMed:17185793].

51. van Oosterom AT, Mattie H, Hermens WT, Veltkamp JJ. The influence of the thyroid function on the metabolic rate of prothrombin, factor VII and factor X in the rat. Thromb Haemost. 1976;35(3):607-19. [PubMed: 989968].

52. Danescu LG, Badshah A, Danescu SC, Janjua M, Marandici AM, Matta $\mathrm{F}$, et al. Venous thromboembolism in patients hospitalized with thyroid dysfunction. Clin Appl Thromb Hemost. 2009;15(6):676-80. doi: 10.1177/1076029609336856. [PubMed: 19671566].

53. Ramagopalan SV, Wotton CJ, Handel AE, Yeates D, Goldacre MJ. Risk of venous thromboembolism in people admitted to hospital with selected immune-mediated diseases: record-linkage study. BMC Med 2011;9:1. doi: 10.1186/1741-7015-9-1. [PubMed: 21219637].

54. Peralta AR, Canhao P. Hypothyroidism and cerebral vein thrombosis-a possible association. J Neurol. 2008;255(7):962-6. doi: 10.1007/s00415-008-0746-5. [PubMed: 18560795].

55. Farid NR, Griffiths BL, Collins JR, Marshall WH, Ingram DW. Blood coagulation and fibrinolysis in thyroid disease. Thromb Haemost. 1976;35(2):415-22. [PubMed: 989641].

56. Chadarevian R, Bruckert E, Ankri A, Beucler I, Giral P, Turpin G. Relationship between thyroid hormones and plasma D-dimer levels. Thromb Haemost. 1998;79(1):99-103. [PubMed: 9459332].

57. Thomas DP, Roberts HR. Hypercoagulability in venous and arterial thrombosis. Ann Intern Med. 1997;126(8):638-44. [PubMed: 9103132]

58. Chadarevian R, Bruckert E, Giral P, Turpin G. Relationship between thyroid hormones and fibrinogen levels. Blood Coagul Fibrinolysis. 1999;10(8):481-6. [PubMed: 10636459].

59. Verkleij CJ, Stuijver DJ, van Zaane B, Squizzato A, Brandjes DP, Buller $\mathrm{HR}$, et al. Thrombin-activatable fibrinolysis inhibitor in hypothyroidism and hyperthyroxinaemia. Thromb Haemost. 2013;109(2):21420. doi: 10.1160/TH12-07-0525. [PubMed: 23197299].

60. Cesarman-Maus G, Hajjar KA. Molecular mechanisms of fibrinolysis. BrJ Haematol. 2005;129(3):307-21. doi: 10.1111/j.1365-2141.2005.05444.x. [PubMed: 15842654].

61. Bouma BN, Mosnier LO. Thrombin activatable fibrinolysis inhibitor (TAFI) at the interface between coagulation and fibrinolysis. Pathophysiol Haemost Thromb. 2003;33(5-6):375-81. [PubMed: 15692247].

62. Ermantas N, Guldiken S, Demir M, Tugrul A. Thrombin-activatable fibrinolysis inhibitor (TAFI) antigen and activity assay in patients with primary hypothyroidism. Clin Appl Thromb Hemost. 2010;16(5):568-73. doi: 10.1177/1076029609350890. [PubMed: 19959491].

63. Guven GS, Kilicaslan A, Oz SG, Haznedaroglu IC, Kirazli S, Aslan D, et al. Decrements in the thrombin activatable fibrinolysis inhibitor (TAFI) levels in association with orlistat treatment in obesity. Clin Appl Thromb Hemost. 2006;12(3):364-8. doi:10.1177/1076029606291403. [PubMed: 16959692].

64. Kitagawa N, Yano Y, Gabazza EC, Bruno NE, Araki R, Matsumoto K, et al. Different metabolic correlations of thrombin-activatable fibrinolysis inhibitor and plasminogen activator inhibitor- 1 in non-obese type 2 diabetic patients. Diabetes Res Clin Pract. 2006;73(2):150-7. doi: 10.1016/j.diabres.2005.12.008. [PubMed: 16458385].

65. Akinci B, Comlekci A, Ali Ozcan M, Demir T, Yener S, Demirkan F, et al. Elevated thrombin activatable fibrinolysis inhibitor(TAFI) antigen levels in overt and subclinical hypothyroid patients were reduced by levothyroxine replacement. Endocr J. 2007;54(1):45-52. [PubMed: 17090955].

66. Erem C, Ucuncu O, Yilmaz M, Kocak M, Nuhoglu I, Ersoz HO. Increased thrombin-activatable fibrinolysis inhibitor and decreased tissue fac- 
tor pathway inhibitor in patients with hypothyroidism. Endocrine 2009;35(1):75-80. doi: 10.1007/s12020-008-9116-4. [PubMed: 18958631].

67. Cetinkalp S, Tobu M, Karadeniz M, Buyukkececi F, Yilmaz C. The effect of hormone replacement treatment on thrombin-activatable fibrinolysis inhibitor activity levels in patients with Hashimoto thyroiditis. Intern Med. 2009;48(5):281-5. [PubMed:19252348].

68. Alioglu B, Kilic N, Simsek E, Dallar Y. Increased thrombin-activatable fibrinolysis inhibitor and decreased tissue factor pathway inhibitor and thrombomodulin levels in children with hypothyroidism. $J$ Clin Res Pediatr Endocrinol. 2012;4(3):146-50. doi: 10.4274/Jcrpe.652. [PubMed: 22985614].

69. Muller B, Tsakiris DA, Roth CB, Guglielmetti M, Staub JJ, Marbet GA. Haemostatic profile in hypothyroidism as potential risk factor for vascular or thrombotic disease. Eur J Clin Invest. 2001;31(2):131-7. [PubMed: 11168451].

70. Dorr M, Robinson DM, Wallaschofski H, Schwahn C, John U, Felix SB, et al. Low serum thyrotropin is associated with high plasma fibrinogen. J Clin Endocrinol Metab. 2006;91(2):530-4. doi: 10.1210/jc.20051786. [PubMed: 16303831].

71. Mohamed-Ali MS, Ahmed RO. Coagulation profiles in hypothyroid and hyperthyroid female patients in Sudan. Saudi Med J. 2008;29(9):1289-93. [PubMed: 18813414].

72. Gursoy A, Ozduman Cin M, Kamel N, Gullu S. Which thyroidstimulating hormone level should be sought in hypothyroid patients under L-thyroxine replacement therapy?. Int J Clin Pract. 2006;60(6):655-9. doi: 10.1111/j.1368-5031.2006.00822.x. [PubMed: $16805747]$.

73. Negrev NN, Radev RZ, Velikova MS, Anogeianaki A. Effects of the hormones of the thyroid axis on the vitamin K-dependent plasma factors of blood coagulation (II, VII, IX, and X). Int J Immunopathol Pharmacol. 2008;21(1):221-6. doi: 10.1177/039463200802100125. [PubMed: 18336749].

74. Stroup DF, Berlin JA, Morton SC, Olkin I, Williamson GD, Rennie D, et al. Meta-analysis of observational studies in epidemiology: a proposal for reporting. Meta-analysis Of Observational Studies in Epidemiology (MOOSE) group. JAMA. 2000;283(15):2008-12. [PubMed: 10789670].

75. Franchini M, Montagnana M, Manzato F, Vescovi PP. Thyroid dysfunction and hemostasis: an issue still unresolved. Semin Thromb Hemost. 2009;35(3):288-94. doi:10.1055/s-0029-1222607. [PubMed: 19452404].

76. Dalton RG, Dewar MS, Savidge GF, Kernoff PB, Matthews KB, Greaves M, et al. Hypothyroidism as a cause of acquired von Willebrand's disease. Lancet. 1987;1(8540):1007-9. [PubMed: 2883346].

77. Erem C. Blood coagulation, fibrinolytic activity and lipid profile in subclinical thyroid disease: subclinical hyperthyroidism increases plasma factor X activity. Clin Endocrinol (Oxf). 2006;64(3):323-9. doi: 10.1111/j.1365-2265.2006.02464.x. [PubMed: 16487444].

78. Kvetny J, Heldgaard PE, Bladbjerg EM, Gram J. Subclinical hypothyroidism is associated with a low-grade inflammation, increased triglyceride levels and predicts cardiovascular disease in males below 50 years. Clin Endocrinol (Oxf). 2004;61(2):232-8. doi: 10.1111/j.13652265.2004.02088.x. [PubMed: 15272919].

79. Lowe GD. Arterial disease and venous thrombosis: are they related, and if so, what should we do about it?. J Thromb Haemost. 2006;4(9):1882-5. doi: 10.1111/j.1538-7836.2006.02130.x. [PubMed: $16848865]$.

80. Agnelli G, Becattini C. Venous thromboembolism and atherosclerosis: common denominators or different diseases?. J Thromb Haemost. 2006;4(9):1886-90. doi: 10.1111/j.1538-7836.2006.02138.x. [PubMed: 16961596].

81. Hostiuc M, Curca GC, Dermengiu D, Sinescu C, Hostiuc S. Can subclinical hypothyroidism explain some sudden deaths due to pulmonary embolism without evident risk factors?. Med Hypotheses. 2011;76(6):855-7. doi: 10.1016/j.mehy.2011.02.035. [PubMed: 21420793].

82. Biondi B, Cooper DS. The clinical significance of subclinical thyroid dysfunction. Endocr Rev. 2008;29(1):76-131. doi: 10.1210/er.2006-0043. [PubMed: 17991805].

83. Tian L, Ni J, Guo T, Liu J, Dang Y, Guo Q, et al. TSH stimulates the proliferation of vascular smooth muscle cells. Endocrine. 2014;46(3):651-8. doi: 10.1007/s12020-013-0135-4. [PubMed: 24452868].

84. Duntas LH, Wartofsky L. Cardiovascular risk and subclinical hypothyroidism: focus on lipids and new emerging risk factors. What is the evidence?. Thyroid. 2007;17(11):1075-84. doi:10.1089/thy.2007.0116. [PubMed: 17900236].

85. Aggarwal S, Sharma N. Cerebral venous sinus thrombosis with autoimmune thyroiditis. Indian JEndocrinol Metab. 2013;17(Suppl1):S1767. doi: 10.4103/2230-8210.119563. [PubMed: 24251149].

86. Canturk Z, Cetinarslan B, Tarkun I, Canturk NZ, Ozden M, Duman C. Hemostatic system as a risk factor for cardiovascular disease in women with subclinical hypothyroidism. Thyroid. 2003;13(10):971-7. doi: 10.1089/105072503322511382. [PubMed:14611707].

87. Squizzato A, Galli L, van Zaane B, Romualdi E, Stuijver DJ, Dentali $\mathrm{F}$, et al. The effect of subclinical hypothyroidism on vitamin K antagonist treatment. Thromb Res. 2012;129(4):520-2. doi: 10.1016/j.thromres.2011.11.009. [PubMed: 22127212].

88. Dorr M, Empen K, Robinson DM, Wallaschofski H, Felix SB, Volzke $\mathrm{H}$. The association of thyroid function with carotid artery plaque burden and strokes in a population-based sample from a previously iodine-deficient area. Eur J Endocrinol. 2008;159(2):145-52. doi: 10.1530/EJE-08-0140. [PubMed: 18495692].

89. Guldiken S, Demir M, Turgut B, Altun BU, Arikan E, Kara M. Global fibrinolytic capacity in patients with subclinical hypothyroidism. Endocr J. 2005;52(3):363-7. [PubMed: 16006731].

90. Erden S, Buyukozturk S, Vural P, Degirmencioglu S. Acute-phase reactans in Hashimoto thyroiditis. Int Immunopharmacol. 2008;8(1314):1863-5. doi: 10.1016/j.intimp.2008.09.007. [PubMed: 18835463].

91. Marongiu F, Conti M, Murtas ML, Mameli G, Sorano GG, Martino E. Activation of blood coagulation and fibrinolysis in Graves' disease. Horm Metab Res. 1991;23(12):609-11. doi: 10.1055/s-2007-1003766. [PubMed: 1778596].

92. Jorde R, Figenschau Y, Hansen JB. Haemostatic function in subjects with mild subclinical hypothyroidism. The Tromso study. Thromb Haemost. 2006;95(4):750-1. [PubMed:16601854].

93. Ochs N, Auer R, Bauer DC, Nanchen D, Gussekloo J, Cornuz J, et al. Meta-analysis: subclinical thyroid dysfunction and the risk for coronary heart disease and mortality. Ann Intern Med. 2008;148(11):832-45. [PubMed: 18490668].

94. Karch A, Thomas SL. Autoimmune thyroiditis as a risk factor for stroke: a historical cohort study. Neurology. 2014;82(18):1643-52. doi: 10.1212/WNL.0000000000000377. [PubMed: 24719488].

95. Marongiu F, Conti M, Murtas ML, Sorano GG, Mameli G, Salis G, et al. Anticardiolipin antibodies in Grave's disease: relationship with thrombin activity in vivo. Thromb Res. 1991;64(6):745-9. [PubMed: 1798963].

96. Carlioglu A, Timur O, Durmaz SA, Ayhan ME. Mean platelet volume in euthyroid patients with Hashimoto's thyroiditis. Blood Coagul Fibrinolysis. 2015;26(3):282-4. doi: 10.1097/MBC.0000000000000236. [PubMed: 25485785].

97. Dentali F, Rancan E, van Zaane B, Gerdes VE, Venco A, Ageno W, et al. The effect of thyroid autoantibodies on warfarin stability. Thromb Res. 2010;126(1):e61-2. doi: 10.1016/j.thromres.2009.09.018. [PubMed: 19822352].

98. Zoller B, Li X, Sundquist J, Sundquist K. Risk of pulmonary embolism in patients with autoimmune disorders: a nationwide follow-up study from Sweden. Lancet. 2012;379(9812):244-9. doi: 10.1016/S01406736(11)61306-8. [PubMed: 22119579].

99. Franchini M, Lippi G, Manzato F, Vescovi PP. Thyroid-associated autoimmune coagulation disorders. J Thromb Thrombolysis. 2010;29(1):87-91. doi: 10.1007/s11239-009-0327-1. [PubMed: 19277469]. 